Vol.61: e18160475, 2018

http://dx.doi.org/10.1590/1678-4324-2018160475

ISSN 1678-4324 Online Edition
BRAZILIAN ARCHIVES OF

BIOLOGY AND TECHNOLOGY

AN INTERNATIONAL JOURNAL

\title{
Effects of clonal integration on the proximal and distal ramets of Cynodon dactylon under shade stress
}

\author{
Tao Ying Shi ${ }^{1}$, Qiu-Mei Quan'*, Yun-Xiang $\mathbf{L i}^{2}$. \\ ${ }^{1}$ University of South China, Changsha, China; ${ }^{2}$ China West Normal University, College of Enviromental Science and \\ Engineering, Nanchong, Sichuan, China
}

\begin{abstract}
In a pot experiment, clonal ramets of Cynodon dactylon, a stolon herbaceous plant, were treated with heterogeneous lighting. Proximal ramets (elder ramets) were subjected to shade stress at three different degrees, and stolons between proximal and distal ramets of each pair were treated in a connected or severed manner. Results showed that in moderate shade stress, the number of ramets and leaves, biomass, net photosynthetic rate (Pn), maximum quantum yield $(F v / F m)$, effective quantum yield of PSII (DPSII), and soil and plant analysis development values (SPAD) of proximal ramets were significantly reduced, regardless of whether stolons were kept intact or severed. However, the growth of distal ramets was not significantly influenced, and keeping the stolons intact also did not bring apparent benefits for the whole clonal fragments. These results show that clonal integration does not help alleviate the shade stress suffered by proximal ramets and the costs of distal ramets and does not significantly influence the whole clonal fragments. The possible reasons are that distal ramets may be at the cost of metabolism for resource transportation when the proximal ramets suffer from shade stress; thus, clonal integration is not favorable.
\end{abstract}

Key words: Clonal integration, shade stress, Cynodon dactylon, proximal ramets

\footnotetext{
*Author for correspondence: meimeiq@163.com
} 
Shi, TY et al

\section{INTRODUCTION}

Clonal plants can adapt to adversity and expand their habitat by clonal integration. Clonal integration refers to the transportation and sharing of materials or resources, such as photosynthetic products, mineral nutrients, and water, from the source to the target among clonal ramets through connection or stolon internodes (Marshall, 1990). Many studies reported that clonal integration can alleviate the negative effects suffered by the distal ramets; for instance, clonal integration can enhance the survivability against flood for the distal ramets of Spartina alterniflora (Yan Xiao et al., 2010).

Cynodon dactylon is a perennial herb belonging to Chlorideae, Eragrostoideae, and Gramineae (Garscher, 1994). It is widely distributed in tropical, subtropical, and temperate regions. Its stolons are buried into the earth or lie horizontally on the ground, whose length is generally 10-110 cm. Meanwhile, its internodes produce adventitious roots downward, and the axillary buds on the internodes grow into branches. C. dactylon develops stolons with strong extending ability, which makes it suitable for soil stabilization. Thus, it is generally used in building lawns or stadiums. C. dactylon is a clonal plant. Previous studies have mainly focused on the function and ecologically adaptive value of clonal integration via comparing and analyzing the differences in survival rates, physiology, morphology, and propagation between the connected and severed ramets.

Clonal integration can help C. dactylon to resist flood (Zhang et al., 2010) and shade stress (Tao et al., 2013). However, few studies have reported the effects of clonal integration on the proximal ramets suffering from stress. In this paper, the effects of clonal integration on the proximal ramets of $C$. dactylon will be discussed. The proximal ramets were subjected to shade stress at three different degrees, and the stolons between the proximal and distal ramets of each pair were treated in a connected or severed manner. The following research questions were used to guide this study: 1) Is there clonal integration between ramet pairs when the proximal ones of $C$. dactylon are under shade stress? 2) Can the connected stolons alleviate the negative effects on the growth suffered by the proximal ramets? 3 ) Will the connected stolons negatively influence the growth of distal ramets?

\section{MATERIALS AND METHODS}

\section{Study area}

The test area, the experimental base of the School of Life Science in China West Normal University, is located at Nanchong, Sichuan $\left(30^{\circ} 14^{\prime}-31^{\circ} 16^{\prime} \mathrm{N}, 106^{\circ}-107^{\circ} 1^{\prime} \mathrm{E}\right.$, altitude: 276 $\mathrm{m})$. This area is characterized by a subtropical monsoon climate, with an annual average temperature of $16.8{ }^{\circ} \mathrm{C}$, relative humidity of $76 \%-86 \%$, annual rainfall of $980-1150 \mathrm{~mm}$, and annual sunlight of $1215-1530 \mathrm{~h}$.

\section{Experimental design}

Six original C. dactylon (plant spacing $>1200 \mathrm{~m}$ ) were collected from the grassland in the benchland of Jia Ling River in Nanchong for cultivation in May 4, 2012. Each of the six replicates was derived from six places. Two ramets obtained from the original C. dactylon, which grew well and had similar sizes, were selected as the research material. The relatively elder ramets in growth were called the proximal ramets, whereas the other one in the pair, distal ramets. Each pair of plastic flower pots with $15 \mathrm{~cm}$ in diameter and $20 \mathrm{~cm}$ in height were filled with equal sandy soil, which were all collected from the benchland of Jia Ling River and compacted to $16 \mathrm{~cm}$ with water. Afterward, we cut a line along each flower pot vertically downward to $0.4 \mathrm{~cm}$ above the surface of sandy soil, where a small hole was made to pull through the stolons of $C$. dactylon. As a result, the proximal and distal ramets of each pair can be planted separately in each pair of flower pots. All the fine lines of each pot were sealed with plastic adhesive tapes to prevent the sand and water from leaking out. After recovery growth for several days, the six treatments were carried as follows (Figure 1): 
Effects of clonal integration on Cynodon dactylon

Proximal ramets Distal ramets Proximal ramets Distal ramets

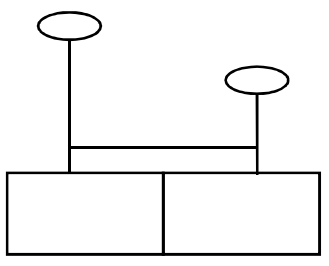

UT-UT
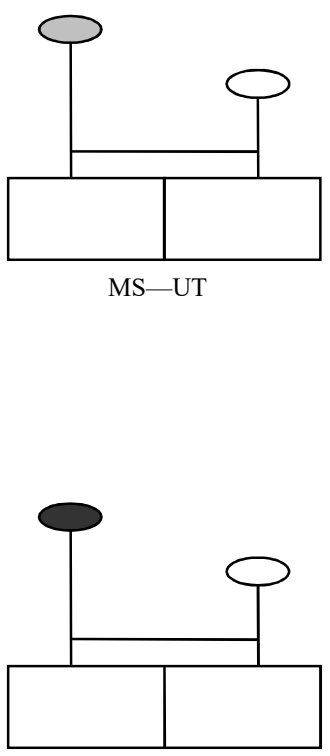

$\mathrm{SS}-\mathrm{UT}$

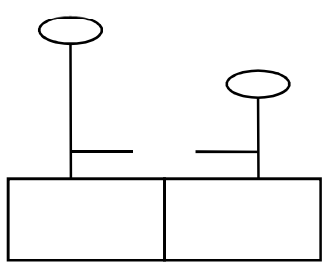

UT\|UT
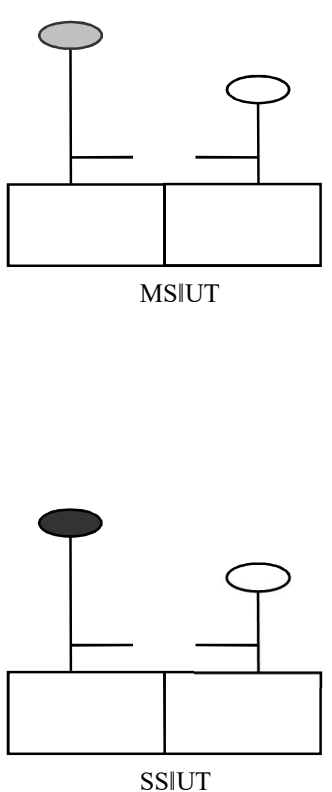

No shade

Moderate shade stress

Serious shade stress

Figure 1: Schematic representation of the experimental design. Full exposure to sunlight: UT-UT: stolon connections are kept intact and proximal ramets are treated with no shade stress (Treatment 1); UT\|UT: stolon connections are kept severed and proximal ramets are treated with no shade stress(Treatment 2); Shade stress (25\% sunlight): MSUT: stolon connections are kept intact and proximal ramets treated with modearate shade stress (Treatment 3); MS $\|$ UT: stolon connections are kept severed and proximal ramets are treated with modearate shade stress (Treatment 4); Serious shade stress ( $5 \%$ sunlight): SS-UT: stolon connections are kept intact and proximal ramets are treated with serious shade stress (Treatment 5); SS\|UT: stolon connections are kept severed and proximal ramets are treated with serious shade stress (Treatment 6).

Full exposure to sunlight: the proximal ramets were treated with no shade stress, stolon connections were kept intact, and proximal ramets were treated with no shade stress (treatment 1: UT-UT). Stolon connections were kept severed, and proximal ramets were treated with no shade stress (treatment 2: UT\|UT).

Shade stress (25\% sunlight): stolon connections were kept intact, and proximal ramets were treated with moderate shade stress (treatment 3: MS-UT). Stolon connections were kept severed, and proximal ramets were treated with moderate shade stress (treatment 4: MS\|UT). Serious shade stress ( $5 \%$ sunlight): stolon connections were kept intact, and proximal ramets were treated with serious shade stress (treatment 5: SS\|UT). Stolon connections were severed, 
and proximal ramets were treated with serious shade stress (treatment 6: SS-UT). Each treatment had six replicates and lasted for four weeks.

\section{Measurement of net photosynthetic rate $(P n)$}

The net photosynthetic rate of leaves was measured two days before the harvest. We measured the completely open leaves at the same or similar location of the unstressed and stressed ramets with LI-6400 (LI-COR Inc., NE, USA). The temperature of leaves was set at $25^{\circ} \mathrm{C}$. The gas was provided by $\mathrm{CO}_{2}$ steel cylinder with an open gas path. The concentration was set at 380 $\mu \mathrm{mol} . \mathrm{mol}^{-1}$. The red and blue lights of a LED were used to control the light intensity at 1200 $\mu \mathrm{mol} . \mathrm{m}^{-2} \cdot \mathrm{s}^{-1}$. We measured the light intensity of living leaves by clamping them. We made a match of the photosynthesis system before measuring each leaf induced by light under measurement for 5-15 min. Until the net photosynthetic rate of leaves remained stable, we recorded the data once every $3 \mathrm{~s}$ up to six times in total, the average of which was calculated. To eliminate the deviations in time, the leaves of three groups were alternatively measured.

\section{Measurement of chlorophyll fluorescence (DPSII)}

Chlorophyll fluorescence was measured at the same day as the net photosynthetic rate. We used a portable fluorometer system (PAM-2100, H. Walz, Effeltrich, Germany) to obtain the fluorescence data from the same location of completely open leaves of the stressed and unstressed ramets. The process was repeated six times. The leaves were pre-darkened with the black leaf clips for $3 \mathrm{~min}$. Basic fluorescence $F_{0}$ was obtained by weak, modulated light of 0.1 $\mu \mathrm{mol} . \mathrm{m}^{-2} . \mathrm{s}^{-1}$, and maximal fluorescence of a dark-adapted leaf $F \mathrm{~m}$ by saturating light pulses of $8000 \mu \mathrm{mol} \cdot \mathrm{m}^{-2} \cdot \mathrm{s}^{-1}$. The maximum quantum yield $(F \mathrm{~V} / F \mathrm{~m})$ and effective quantum yield of PSII ( $\Phi P S I I)$ were obtained at the same time.

\section{Measurement of chlorophyll content (SPAD)}

Chlorophyll content was measured with a portable chlorophyll fluorometer (SPAD-502, Minolta Co., Japan). It was obtained at the same or similar positions of stressed and unstressed leaves.

\section{Measurement of the growth and morphological indexes}

Before the end of experiment, we calculated the number of ramets and leaves of each proximal and distal ramet produced during the experiment. We measured the length of stolons with a vernier caliper after straightening each proximal and distal ramet. We calculated and recorded the number of internodes, as well as the average length of internodes. Afterward, we cleaned the stressed and unstressed ramets of each clonal fragment, numbered and enveloped them, and placed them into the drying oven at $70{ }^{\circ} \mathrm{C}$ for $48 \mathrm{~h}$ to their constant weight. The dried materials were weighed on the balance scale with a precision of $0.0001 \mathrm{~g}$.

\section{Data analysis}

We used SPSS 17.0 (SPSS Inc., USA) to carry out two-way analysis of variance (ANOVA) to compare the effects of stolons kept connected or severed and shade treatment on each index and their interaction. We used one-way ANOVA to compare the differences of the same index between different treatments with Bonferroni to make multi-repeated comparison between the means. A 0.05 alpha level of significance was chosen as the cutoff point to test the null hypothesis.

\section{RESULTS \\ Performance of proximal ramets}

As shown in Tables 1 and 2, while the treatment of severed stolons brought insignificant difference, shade stress had significant effects on the length of stolons, number of ramets and leaves, biomass, net photosynthetic rate $(P \mathrm{n})$, maximum quantum yield $(F \mathrm{v} / F \mathrm{~m})$, effective quantum yield of PSII ( $\Phi P S I I)$, and chlorophyll content (SPAD values) of the proximal ramets. 
The interaction of the two treatments also had no significant influence on the above-mentioned indicators.

Table 1. Results of two-way analysis of variance on the effects of stolon severing (Se),shade (Sh) and their interaction $(\mathrm{Se} \times \mathrm{Sh})$ on Length of stolons, Number of ramets, Number of leaves and biomass of the proximal, distal ramets and /or the whole clonal fragments of Cynodon dactylon $(\mathrm{n}=36)$

\begin{tabular}{|c|c|c|c|c|c|c|}
\hline & Treatment & $\mathrm{df}$ & $\begin{array}{l}\text { Length of } \\
\text { stolons }\end{array}$ & $\begin{array}{l}\text { Number of } \\
\text { ramets }\end{array}$ & $\begin{array}{l}\text { Number of } \\
\text { leaves }\end{array}$ & Biomass \\
\hline \multirow{3}{*}{$\begin{array}{l}\text { Proximal } \\
\text { ramets }\end{array}$} & $\mathrm{Se}$ & 1,30 & $3.923^{\mathrm{ns}}$ & $0.548^{\mathrm{ns}}$ & $0.297^{\mathrm{ns}}$ & $0.299^{\mathrm{ns}}$ \\
\hline & $\mathrm{Sh}$ & 2,30 & $393.636^{* * *}$ & $156.062^{* * *}$ & $334.004^{* * *}$ & $\underset{*}{282.187^{* *}}$ \\
\hline & $\mathrm{Se} \times \mathrm{Sh}$ & 2,30 & $2.608^{\mathrm{ns}}$ & $0.034^{\mathrm{ns}}$ & $0.302^{\mathrm{ns}}$ & $0.85^{\mathrm{ns}}$ \\
\hline \multirow{3}{*}{$\begin{array}{l}\text { Distal } \\
\text { ramets }\end{array}$} & $\mathrm{Se}$ & 1,30 & $1.424^{\mathrm{ns}}$ & $0.014^{\mathrm{ns}}$ & - & $0.154^{\mathrm{ns}}$ \\
\hline & $\mathrm{Sh}$ & 2,30 & $0.302^{\mathrm{ns}}$ & $0.13^{\mathrm{ns}}$ & $0.03^{\mathrm{ns}}$ & $0.272^{\mathrm{ns}}$ \\
\hline & $\mathrm{Se} \times \mathrm{Sh}$ & 2,30 & $0.765^{\mathrm{ns}}$ & $0.101^{\mathrm{ns}}$ & $0.249^{\mathrm{ns}}$ & $0.084^{\mathrm{ns}}$ \\
\hline \multirow{3}{*}{$\begin{array}{l}\text { Whole } \\
\text { clonal } \\
\text { fragments }\end{array}$} & $\mathrm{Se}$ & 1,30 & $0.205^{\mathrm{ns}}$ & $0.238^{\mathrm{ns}}$ & $0.054^{\mathrm{ns}}$ & $0.008^{\mathrm{ns}}$ \\
\hline & $\mathrm{Sh}$ & 2,30 & $149.076^{* * *}$ & $46.314^{* * *}$ & $72.453^{\mathrm{ns}}$ & $68.652^{* * *}$ \\
\hline & $\mathrm{Se} \times \mathrm{Sh}$ & 2,30 & $2.527^{\mathrm{ns}}$ & $0.067^{\mathrm{ns}}$ & $0.086^{\mathrm{ns}}$ & $0.037^{\mathrm{ns}}$ \\
\hline
\end{tabular}

Table 2. Results of two-way analysis of variance on the effects of stolon severing (Se),shade (Sh) and their interaction $(\mathrm{Se} \times \mathrm{Sh})$ on Pn, Fv/Fm, ФPS II and SPAD values of the proximal, distal ramets and /or the whole clonal fragments of Cynodon dactylon

\begin{tabular}{ccccccc}
\hline & Treatment & df & $P \mathrm{n}$ & $F \mathrm{~V} / F \mathrm{~m}$ & $\Phi P S I I$ & SPAD values \\
\hline $\begin{array}{c}\text { Proximal } \\
\text { ramets }\end{array}$ & $\mathrm{Se}$ & 1,30 & $2.009^{\mathrm{ns}}$ & $0.226^{\mathrm{ns}}$ & $0.612^{\mathrm{ns}}$ & $0.937^{\mathrm{ns}}$ \\
& $\mathrm{Sh}$ & 2,30 & $2858.702^{* * *}$ & $130.831^{* * *}$ & $217.209^{* * *}$ & $84.524^{* * *}$ \\
& $\mathrm{Se} \times \mathrm{Sh}$ & 2,30 & $1.469^{\mathrm{ns}}$ & $0.122^{\mathrm{ns}}$ & $1.205^{\mathrm{ns}}$ & $1.941^{\mathrm{ns}}$ \\
$\begin{array}{c}\text { Distal } \\
\text { ramets }\end{array}$ & $\mathrm{Se}$ & 1,30 & $2.253^{\mathrm{ns}}$ & $1.555^{\mathrm{ns}}$ & $2.971^{\mathrm{ns}}$ & $1.956^{\mathrm{ns}}$ \\
& $\mathrm{Sh}$ & 2,30 & $2.352^{\mathrm{ns}}$ & $0.230^{\mathrm{ns}}$ & $2.382^{\mathrm{ns}}$ & $2.183^{\mathrm{ns}}$ \\
& $\mathrm{Se} \times \mathrm{Sh}$ & 2,30 & $0.002^{\mathrm{ns}}$ & $0.274^{\mathrm{ns}}$ & $1.558^{\mathrm{ns}}$ & $0.210^{\mathrm{ns}}$ \\
\hline$*{ }^{\mathrm{ns}} \mathrm{P}<0.001,{ }^{* * *}, \mathrm{P}<0.01,{ }^{*}, \mathrm{P}<0.05 ;{ }^{\mathrm{ns}}, \mathrm{P}>0.05$ & & & &
\end{tabular}

\section{Performance of distal ramets}

For the distal ramets, the treatment of shade stress and severed stolons, as well as their interaction, exerted no significant effects on the length of stolons, number of ramets and leaves, biomass, net photosynthetic rate $(P \mathrm{n})$, maximum quantum yield $(F \mathrm{v} / F \mathrm{~m})$, effective quantum yield of PSII ( $\Phi P S I I)$, and chlorophyll content (SPAD values) (Tables 1 and 2 ).

As shown in Figure 2A-D, in the circumstance of moderate shade stress, while the number of stolons grew significantly larger, the number of ramets and leaves, as well as the biomass, 
significantly decreased. In Figure 3A, C, and D, moderate shade stress led to significant decrease in the net photosynthetic rate $(P \mathrm{n})$, effective quantum yield of PSII ( $P P S I I)$, and chlorophyll content ( $S P A D$ values); however, no difference in the maximum quantum yield $(F \mathrm{~V} / F \mathrm{~m})$ was observed (Figure $3 \mathrm{~B})$. Under serious shade stress, significant decrease was observed in the length of stolons, number of ramets and leaves, biomass, net photosynthetic rate $(P \mathrm{n})$, maximum quantum yield $(F \mathrm{~V} / F \mathrm{~m})$, effective quantum yield of PSII ( $P P S I I)$, and chlorophyll content ( $S P A D$ values) of the proximal ramets by comparing Figure $2 \mathrm{~A}-\mathrm{D}$ with Figure $3 \mathrm{~A}-\mathrm{D}$.

A

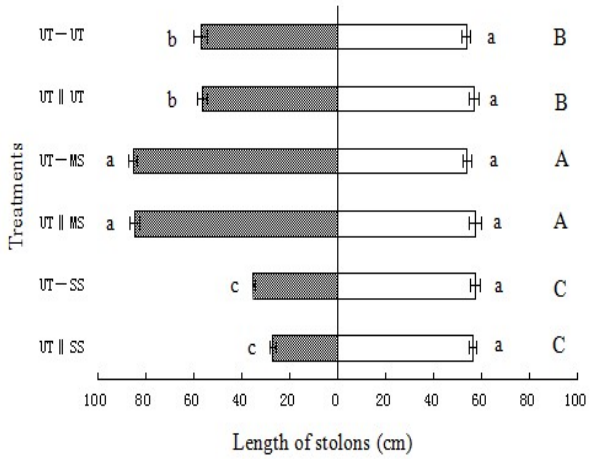

$\mathrm{C}$

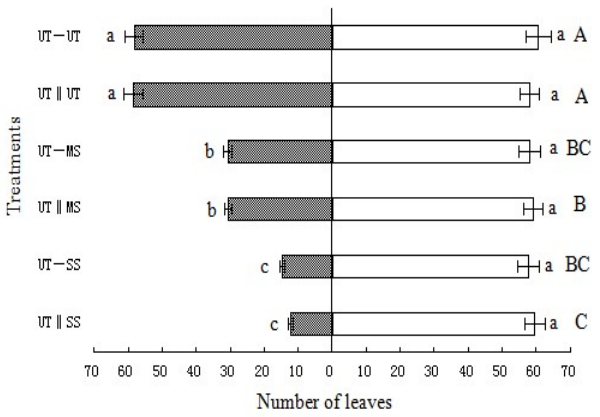

B

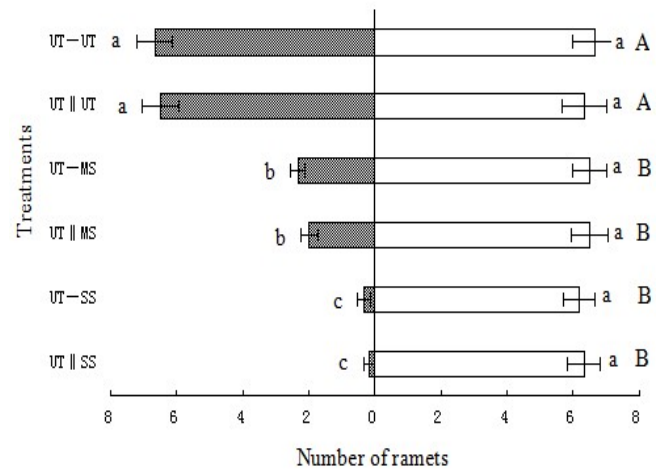

$\mathrm{D}$

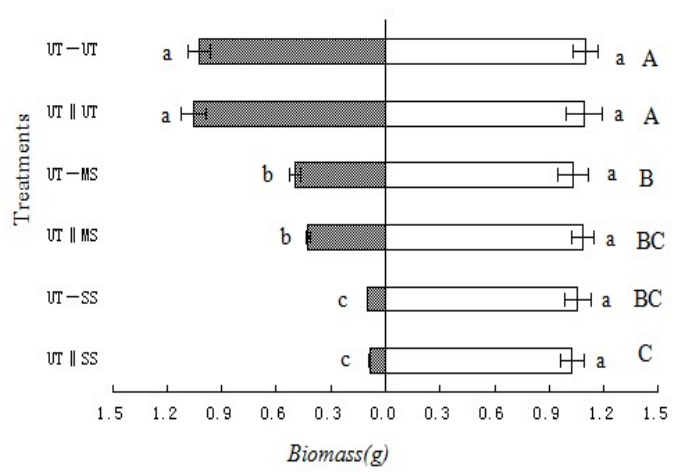

\section{Proximal ramets $\square$ Distal ramet}

Figure 2 Length of stolons (A), number of ramets (B), number of leaves (C) and biomass (D) of the proximal ramets, distal ramets and clonal fragments $(\mathrm{Mean} \pm \mathrm{SE})$. The bars with the same lower case letters are not significantly different at $P<0.05$; for the whole clonal fragments, the same capital letters are not significantly different at $P<0.05$. Treatments are coded as in Figure 1. 
A

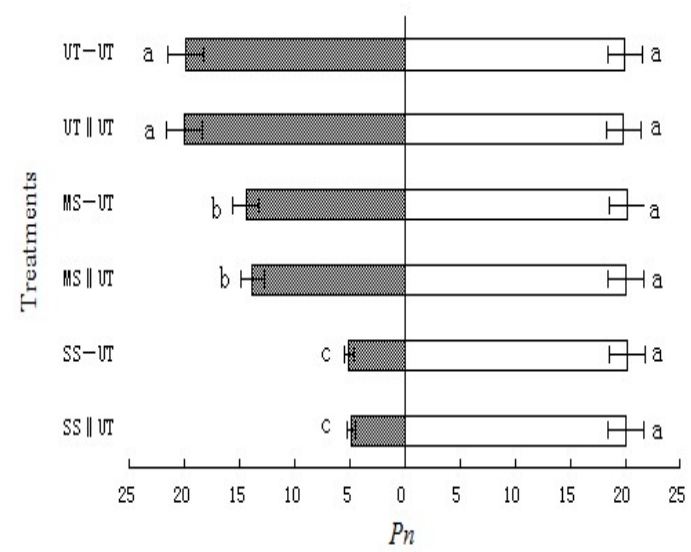

$\mathrm{C}$

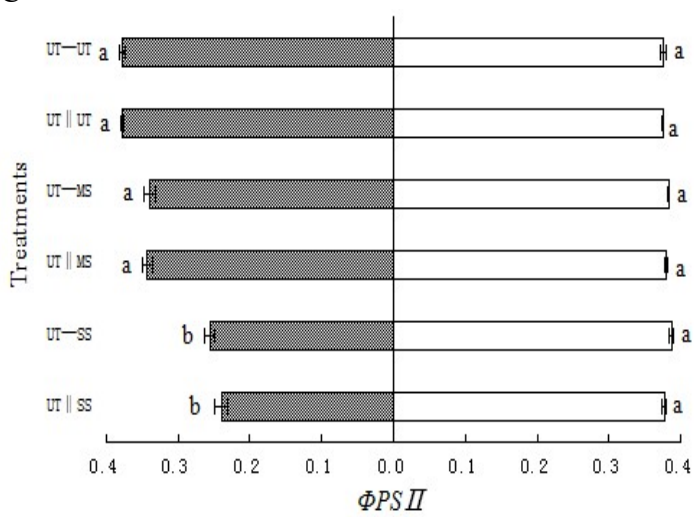

B

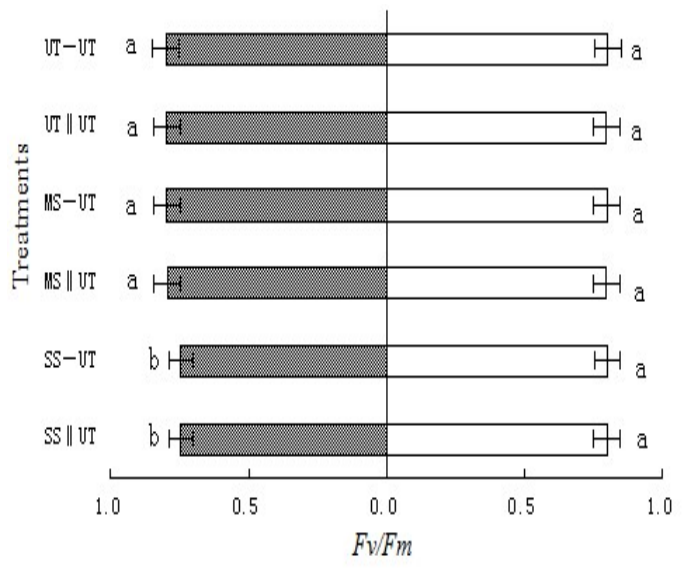

$\mathrm{D}$

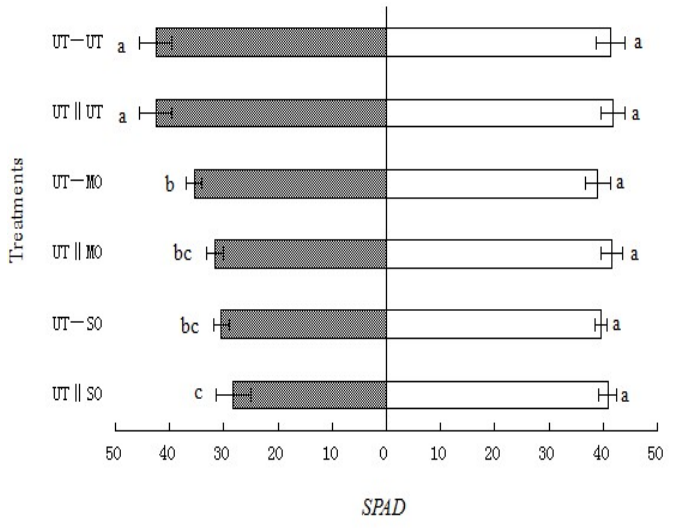

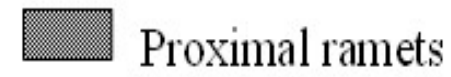

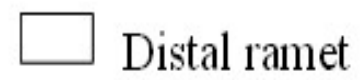

Figure 3. Net photosynthetic rate $P n(\mathrm{~A})$, the maximum quantum yield $F v / F m(\mathrm{~B})$, the effective quantum yield $\Phi P S I I$ (C) and chlorophyll content $S P A D$ values (D) of the proximal ramets and distal ramets (mean \pm SE.).The bars with the same lower case letters are not significantly different at $\mathrm{P}<0.05$; Treatments are coded as in Figure 1 .

\section{Performance of the whole clonal fragment}

As shown in Table 1, the treatments of stolon severing and shade stress have no interactive influence on the length of stolons, number of ramets and leaves, and biomass of the whole clonal fragment. Shade stress led to significant decrease in the number of ramets and leaves and biomass of the whole clonal fragment, but stolon severing exerted no influence (see Figure 2B-D). Under moderate shade stress, the length of stolons of the whole clonal fragment apparently increased, but it significantly decreased in serious shade stress (see Figure 2A).

\section{DISCUSSION}

In this work, the influence of clonal integration on the growth of C.dactylon under heterogeneous lighting condition was studied. We observed that clonal integration caused the compensatory increase of the photosynthetic rate of unstressed proximal ramets. Previous researchers have found that physiological integration of $C$. dactylon enhances its tolerance to flooding (Li et al., 2014). However, other studies demonstrated that there were negative relations between the growth of clonal ramets in patches. Wang et al. (2008) found that clonal integration has minimal contribution to Alternanthera's competitive ability but it affects its growth, photosynthetic efficiency, and biomass allocation. However, the connected stolons of 
Fragaria chiloensis ramets can enhance the growth under low light but apparently weaken the growth of ramets under intense light (Wang, 2009). Our experimental study showed that regardless of whether the stolons were connected or severed, shade stress significantly influenced the growth of the proximal ramets, reducing the number of ramets and leaves, biomass, net photosynthetic rate $(P \mathrm{n})$, maximum quantum yield $(F \mathrm{~V} / F \mathrm{~m})$, effective quantum yield of PSII ( $\Phi P S I I)$, and chlorophyll content ( $S P A D$ values). These results revealed that no physiological integration was observed between the clonal ramet pairs when the proximal ramets of $C$. dactylon were under shade stress, and the connected stolons could not alleviate the negative effects of shade stress on the growth of proximal ramets.

Some studies have shown that the photosynthetic products, water, nutrients, and other resources can be transported and shared among the clonal ramets through the stolons or roots (Marshall C., 1990). However, our experimental results revealed that the resources, such as photosynthetic product, in clonal plants did not transfer to the base; that is, the resources, such as nutrients of distal ramets growing in habitats full of light, did not transfer to the proximal ramets growing in the habitats lacking light. In addition, regardless of whether the ramets were under serious or moderate shade stress, stolon severing could not effectively support the growth of proximal ramets. The above results showed that the photosynthetic product was not transported and shared between the distal ramets full of light and proximal ramets. The intensity of heterogeneous environment for the proximal ramets did not provide drive to realize significant physiological integration. The original source-sink relations were not strengthened or weakened, and the direction and quantity of the material transportation were also not changed between the connected ramets, which may also be caused by the physiological integration, inevitably paying cost and loss. This result may be related to the structure of xylogen and phloem of $C$. dactylon, hindering the base-oriented material transportation.. The interruption of the integration of proximal ramets under environmental stress can be conducive to reduce the consumption of resources in the process of transfer. Thus, more resources can be used to sustain the growth and propagation of the distal ramets themselves, which can be considered as a risk-spreading strategy. De Kroon (1995) pointed out that in the process of physiological integration, one ramet of clonal plants sustains its growth by sacrificing benefits of the other ramet. However, when such loss exceeds their tolerance and adaptation abilities, the risk-spreading capability of clonal plants will not be enough to resist death risk of the genets, whose extinction is inevitable (Chen and Dong, 2004). Therefore, in this experiment, clonal integration might bring potential costs for the consumption of distal ramets; evolutionarily and adaptively, it may be the best choice for the genets to reduce or interrupt physiological integration, which can help reduce the consumption in the process of resource transportation (Li, 2003).

In the present study, as no resource sharing or weak sharing ability existed in clonal ramets, the connected stolons did not alleviate the negative effects of shade stress on the proximal ramets and caused no significant loss of the distal ramets and the whole clonal fragment. Possible reasons are as follows: When the proximal ramets suffered from shade stress, resource transportation of the distal ramets had metabolic costs, so it was unfavorable for clonal integration. The resource transportation between clonal ramets is characterized by a certain direction. The material transmission of acropetal orientation is far more common than that of basipetal orientation. Such patterns of resource use may also be related to the specific structures of vascular bundle and nutrient transmission processes of $C$. dactylon. When the proximal ramets suffered from shade stress, the distal ramets interrupted the physiological integration between them and lived independently to spread the death rate of genets to each ramet, resulting in advantages in evolution. The ramets realized risk spreading by dying alone and changing their action as well as storing resources (Gross, 1995). Clonal integration remains to be elucidated. As the process and mechanism of clonal integration are complex, further research on the cost-benefit relationship of resources, clonal rate, and regulation system from the perspectives of enzymes, hormones, and genetic expression is needed. Such studies will be meaningful to reveal the growth, development, adaptive strategies, and laws of life activities of clonal plants.

\section{CONCLUSIONS}

The clonal ramets of $C$. dactylon did not help alleviate the shade stress suffered by the proximal ramets and the costs of the distal ramets. Thus, clonal integration was not favorable in this 
Effects of clonal integration on Cynodon dactylon

species. The results of this study have great importance to reveal the growth, phylogeny, adaptive strategies, and law of life activities of clonal plants.

\section{ACKNOWLEDGMENTS}

We are very grateful to Prof. Jing-Song Chen and Yong-Mei Liao for the instruction and help. This work was supported by the project initiated from China West Normal University, the project (2015JY0140) from the Science and Technology Department of Sichuan province, and the double first-class construction project of the University of South China.

\section{REFERENCES}

1. Alpert P. Water sharing among ramets in a desert poplation of Distichitaspicata (Psaceae). American Journal of Botany. 1990; 77: 1648-1651.

2. Chen J. S., M. Dong, D. Yu, and Q. Liu. Intraclonal spatial division of labour in two stoloniferous plants with different branching type in response to reciprocal patchiness of resources. Acta Ecologica Sinica. 2004; 24 (5): 920-924.

3. De Kroon H., and M. J. Hutchings. Morphological plasticity in clonal plants: the foraging concept reconsidered. Journal of Ecology. 1995; 83(1): 143-152.

4. Gross K. L., Pregitzer K. S., Burton A. J. Spatial variation in nitrogen availability in three successional plant communities. Journal of Ecology. 1995; 83: 357-367.

5. Li D., Takahashi S. Particularities of clonal plant species induced by physiological integration. Grass Sci. 2003; 49(4): 395-402.

6. Marshall C. Source-sink relations of interconnected ramets (In: Clonal Growth in Plants: Regulation and Function, Eds: van Groenendael J., H. de Kroon) -The Hague, Academic Publishing. 1990; 23-41.

7. Pitelka L. F., Hansen S. B., Ashmun J. W. Population biology of clintonia borealis I. Ramet and patch dynamics. Journal of Ecology. 1985; 73(1): 169-183.

8. Price E. A. C., Hutchings M. J. The causes and developmental effects of integration and indepence between different parts of Glechoma hedercea clones. Oikos. 1992; 63: 376386.

9. Pitelka L. F., Hansen S. B., Ashmun J. W.Population biology of clintonia borealis I. Ramet and patch dynamics. Journal of Ecology. 1985; 73(1): 169-183.

10. Schmid B., Bazzaz F. A. Clonal intergration and population structure in perennials: effects of severing rhizome connections. Ecology. 1987; 68: 2016-2022.

11. Shumway S. W. Physiological integration among clonal ramets during invasion of disturbance patches in a New England salt marsh. Annuals of Botany. 1995; 76(3): $225-$ 233.

12. Tao Y. S., Hong S. C., Liao Y. M., Li Y. X., Liao X. L., Quan Q. M. Cost-benefits of the clonal integration of Cynodon dactylon, a stolon herbaceous plant, under heterogeneous lighting condition. Acta Ecologica Sinica.2013; 33(20): 6509-6516.

13. Wang N., Yu F. H., Li P. X., He W. M., Liu J., Yu G. L., Song Y. B., Dong M. Clonal integration supports the expansion from terrestrial to aquatic environments of the amphibious stoloniferous herb Alternanthera philoxeroides. Plant Biology. 2009; 11: 483489.

14. Yan X., Tang J. B., Qing H. Clonal integration enhances flood tolerance of Spartina alterniflora daughter ramets. Aquatic Botany. 2010; 92(1): 9-13.

15. Zhang X. Y., Fan D. Y., Xie Z. Q., Xiong G. M., Li Z. J. Clonal integration enhances performance of Cynodon dactylon subjected to submergence. Chinese Journal of Plant Ecology. 2010; 34 (9): 1075-1083.

16. Li Z.J., Fan D.Y., Chen F.Q., Yuan Q.Y., Chow W.S., Xie Z.Q. Physiological integration enhanced the tolerance of Cynodon dactylon to flooding. Plant Biol (Stuttg). 2015; 17(2): 459-465.

17. Wang N., Yu F.H., Li P.X., He W. M., Liu F.H., Liu J.M., Dong M. Clonal integration affects growth, photosynthetic efficiency and biomass allocation, but not the competitive ability, of the alien invasive Alternanthera philoxeroides under severe stress. Ann Bot. 2008; 101(5): 671-678. 